\title{
The importance of folk-linguistic approaches in the study of dialectal phenomena
}

\author{
Cameron Morin \\ Department of English, Ecole Normale Supérieure Paris-Saclay, France \\ https://doi.org/10.36505/ExLing-2018/09/0020/000353
}

\begin{abstract}
As the traditional distinction between the studies of linguistic competence and performance (Chomsky 1965) seems increasingly outdated, so is the separation between theory and practice in disciplines of linguistics equally undesirable, especially in the field of dialectology. As an illustration thereof, this paper aims to present the virtues of the alternative, underutilised approach of folk linguistics (Niezielski \& Preston 2010), in the shape of a questionnaire for judgment data elicitation about various implications surrounding double modals (DM) in Borders Scots. By detailing the methodology and results of this questionnaire, carried out in January 2018, it will be shown that many dialectal phenomena in English, including multiple modality (MM), absolutely require such sources of evidence to reach a convincing state of analysis.

Key words: folk-linguistics, dialectology, judgment data, questionnaire, modality
\end{abstract}

\section{Introduction}

For a tremendous amount of specific linguistic features, the foremost approach to their study is the search for patterns of occurrence in a corpus, conceived as "a collection of pieces of language that are selected and ordered according to explicit linguistic criteria in order to be used as a sample of the language" (Sinclair 1996: 4). Recent progress in informatics has led to the primacy of "computer corpora", "encoded in a standardised and homogenous way for open-ended retrieval tasks", and it has resolved the obvious shortcomings of 'toy' systems in theoretical linguistics. Yet it is apparent that a vast range of linguistic phenomena cannot be grasped by way of corpus-based methodologies, for simple reasons including that they may be i) as of yet improperly recorded and transcribed if they are rare, ii) part of an essentially oral nonstandard language variety, or iii) lacking a consensual written form altogether.

This paper aims to show the advantages of an alternative, underrated approach labelled folk-linguistic, the core principles of which are the speaker's competence in metalinguistic judgments and the elicitation of said judgments by the researcher in the speech communities concerned. Many folk-linguistic assumptions are usually shared and applied in the various branches of sociolinguistics; the novelty of this paper is to also

ExLing 2018: Proceedings of 9th Tutorial and Research Workshop on Experimental Linguistics, 28-30 August, Paris, Frannce 
show how an appropriate usage can help resolve deep theoretical issues raised by features licensed in the distant periphery of a given language, viz. in dialects. The case study in support of these arguments is that of multiple modality (MM) in Modern Scots, through the example of a questionnaire for judgment data elicitation vis-à-vis this phenomenon.

\section{What is folk linguistics?}

Hoenigswald (1966) was the first to formulate the basic principles underlying the experimental school of folk linguistics, namely that we should add to descriptions of "what goes on", i.e language, analyses of "(b) how people react to what goes on and (...) (c) what people say goes on (talk concerning language)" (20). Native speakers of a language variety may indeed have much more linguistic knowledge than we sometimes give them credit for: for instance, they are aware of notions such as reference, morphological segmentability, pragmatic presupposition for anaphora, meanings of linguistic items independent of context and inference of direct speech acts (Niedzielski and Preston 2000: 10-16; Silverstein 1981). The researcher must compensate with their own expertise the disadvantages inherent to judgment data, esp. that they should be subjective and potentially impoverished by inaccuracy or lack of terminology speakers have at their disposal to enrich them. Methods of elicitation are therefore confronted with the challenge of being sufficiently clear and precise to capture the kind of judgment needed for a study's purposes without orienting the speaker's reasoning too much and risking denaturation of the subsequent judgment. This balance, to be respected in every encounter between the researcher and the speaker, is sometimes a delicate affair.

\section{A typical means of folk-linguistic experimentation}

It naturally follows that folk linguistics, and more generally sociolinguistics, heavily rely on fieldwork to elicit satisfactory amounts of qualitative judgment data. Data collection is to be done in vivo, i.e through interaction with a sample of speakers representing a linguistic community using a set of objective and reliable tools. The most common of these tools is the questionnaire, as the systematic fashion in which it collects data allows for quantitative analysis afterwards (Calvet \& Dumont 1999; Johnstone 2000). While fact questions are supposed to relate to empirically verifiable phenomena, psychological questions relate to opinions, motivations and attitudes. Formally, questions can be closed (yes/no), semi-closed (multiple choice) or open: this determines whether 
the questionnaire overall is structured or non-structured. Multiplying the subtypes of collectable judgment is of much importance to give a fuller, pluridimensional approach to the analysis of the linguistic feature at hand. Other methodological guidelines include the systematicity of the questionnaire, i.e that the same form should be given to each and every sub-group of the sample; the brevity of the questionnaire, so that it should not take more than fifteen minutes to complete in order to keep the speaker focused and invested; and the simplicity of the questions, which implies one idea per sub-task formulated in an easily understandable manner (e.g by avoiding jargon). Finally, questions are required to be neutral, in that they should not withhold any kind of prejudice on the part of the researcher with respect to the research topic concerned and its conclusions.

\section{Folk linguistics and double modals in Modern Scots}

Being an essentially oral and basilectal feature also found in other nonstandard varieties of American and British English, Scottish DMs (typically might could, or will can) are impossible to capture by way of contemporary digital corpora (there are next to 0 hits in the corpora available at the Angus McIntosh Centre for Historical Linguistics (Edinburgh)), and previous abstracted accounts of their syntax, semantics and pragmatics have either failed or not been properly undertaken. One solution to this problem is the elicitation of judgment data. A field mission was carried out over three days and nights from the 10th to the 13th January 2018 in the town of Hawick, one of the larger towns in the Borders where MM in Scots has been most extensively studied (Brown 1990; Bour 2014). Its main tasks were the following:

(0) Knowledge of the age, gender, activity and living area of the subject

(1) Knowledge of how the subject represents the geography of their language variety

(2) (2) Recognition and usage of typical DM structures

(3) Syntactic manipulation of DM structures into negatives and questions,

(4) Pragmatic and sociolinguistic information about the current usage of DMs

(5) Recognition and usage of all DMs attested previously in the literature (see Morin 2018 for a full version of the form)

Prior to the field mission, 120 questionnaires had been printed and divided into four stacks of 30 each, three of which were dropped off and regularly checked in central institutions or locations of Hawick while the last stack was personally brought to hosts, proprietors of local shops and businesses during the day, and inhabitants met in public places such as 
parks, benches on the roadside, cafes, etc. 61 questionnaires were completed and compiled.

\section{Results}

The small scale of the experiment is in stark contrast with the wealth of data it provided, relatively to previous research: it showed that contra many preconceptions, DMs are still an active component of Borders Scots; it has also led to several hypotheses on a number of (voluntarily ideal-typical) levels:

(a) The syntax of DMs may rely on a context-dependent speaker's choice

(b) DMs may have more assertive strength than standard modal structures, and their semantics map onto those of American DMs

(c) DMs are informal, local and familial features that have adapted to the revolutions of the Internet and social networks

(d) they may partake in the construction of a distinct sociolinguistic identity, for instance through the medium of humour.

\section{Conclusions}

The principles of folk linguistics and their experimental methods need to be encouraged in dialectology, sociolinguistics, and as has been shown in the previous section, even beyond. It appears as a highly valuable, even necessary resource in the study of non-written linguistic phenomena; and it may very well be a precious complement to more theoretically-driven disciplines of linguistics, for instance in studies of grammatical core and periphery in which MM needs to be more deeply seated.

\section{References}

Bour, A. 2014. Description of Multiple Modality in Contemporary Scotland: Double and Triple Modals in the Scottish Borders. PhD dissertation, University of Freiburg.

Brown, K. 1991. Double modals in Hawick Scots. In Trudgill, P., Chambers, J.K. (Eds.), Dialects of English, 74-103. London: Longman.

Chomsky, N. 1965. Aspects of the Theory of Syntax. Cambridge: MIT Press.

Hoenigswald, H. 1966. A proposal for the study of folk-linguistics. In Bright, W. (Ed.), Sociolinguistics 16-26. The Hague: Mouton.

Johnstone, B. 1999. Qualitative Methods in Sociolinguistics. Oxford University Press.

Morin, C. 2018. Questionnaire for eliciting judgment data on the recognition and usage of double modals in Hawick (Scotland), TulQuest, Paris: CNRS.

Niedzielski, N.A., Preston, D. 2010. Folk Linguistics. Berlin \& New York: Mouton de Gruyter.

Silverstein, M. 1981. The limits of awareness. Sociolinguistic Working Papers 84, Austin, Texas: Southwest Educational Development Laboratory.

Sinclair, J. 1996. EAGLES: Preliminary recommendations on Corpus Typology, EAGLES Document EAG TCWG-CTYP/P. 